\title{
Mass Spectrometry: An Essential Tool for the Flavor and Fragrance Industry
}

\author{
Frédéric Begnaud*
}

\begin{abstract}
Over the past decades, mass spectrometers have become standard instruments in the analytical laboratories of the flavor and fragrance (F\&F) industry. As the expansion of the fields of use of flavors and fragrances and the launch of numerous new technologies designed to enhance their performance have led to a diversification and increased complexity of the questions asked to the analytical chemists, mass spectrometry remains an essential tool to address them. The capabilities of the latest generation of instruments combined with advanced molecular separation and data processing tools allow to tackle many of these challenges. Through different examples, and focusing on the period that followed our 2014 review ${ }^{[1]}$ this article illustrates different ways MS is contributing to the discovery, development and commercialization of F\&F ingredients and technologies, for both volatile and non-volatile molecules.
\end{abstract}

Keywords: Analytical sciences · Flavor and fragrance industry · Mass spectrometry

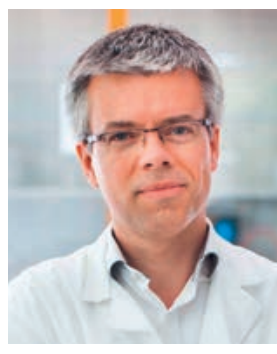

Dr. Frédéric Begnaud is Director of Analytical chemistry in the R\&D of Firmenich, the largest privately-owned perfume and taste company, and is in charge of Global Analytical Excellence. Over his previous 18 years at Firmenich, he developed a sound expertise in theoretical and practical analytical chemistry, especially in separation science for volatile and non-volatile organic compounds analysis. He is especially passionate about how excellence in science can dramatically impact business success.

\section{The Critical Role of Mass Spectrometry in F\&F Research and Development}

Creating consumer-preferred flavors or fragrances involves many steps. A broad range of ingredients with the best olfactive or taste attributes has to be made available on the palette of the flavorists and perfumers, some of them newly discovered and launched, and their compliance and quality must be ensured. Then comes, through a combination of artistry and scientific design, the elaboration of the delicate balance between tens or hundreds of volatile and non-volatile raw materials to generate the perfect accord that will delight the customer. Beyond this creation aspect, the importance of leveraging advanced technologies that will maximize the performance of the fragrances and flavors, for example, through higher stability or control of their delivery kinetics has become critical and raises new analytical challenges. In view of this evolution, volatile analysis is no longer the alpha and omega of the analytical chemistry activities of F\&F houses. Non-volatile investigations have become critical and represent today a very substantial part of analytical activities. At the heart of all this is mass spectrometry (MS). The versatility of the mass spectrometers, the efficiency of their couplings with both gas and liquid chromatographs, and their different ionization modes enabling high sensitivity and selectivity, make them ubiquitous in any F\&F analytical laboratory (Fig. 1). MS is nowadays a standard detector, as the flame ionization detector (FID) used to be in the second half of the $20^{\text {th }}$ century.

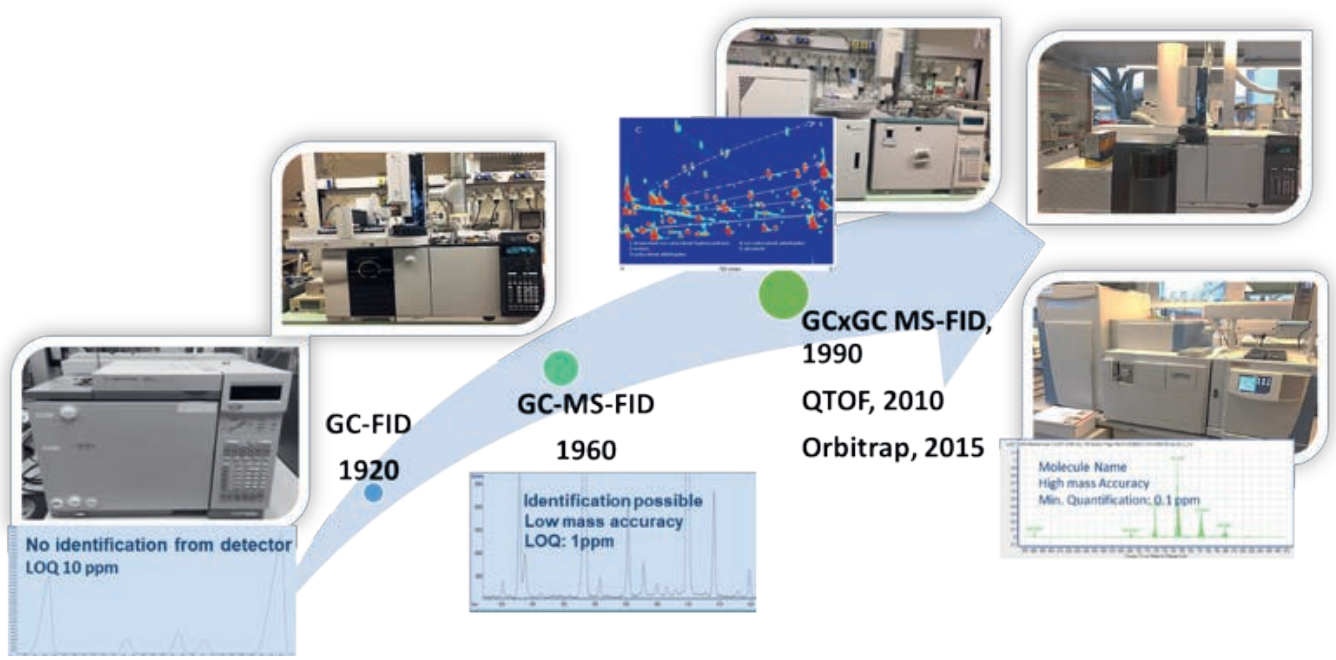

Fig. 1. Evolution of GCMS in F\&F laboratories. 
In the early days, the term mass spectrometry mainly referred to the instruments themselves. Massive, highly demanding in energy, they required highly skilled and dedicated scientists to operate them in the late 1950s. Their sensitivity, selectivity and versatility rapidly contributed to their popularity in all laboratories dealing with the identification and then quantification of trace amounts. Instrument suppliers massively invested in this new technology, and the technique evolved rapidly. A global ecosystem was created and nowadays MS capabilities imply a combination of the instrument, operating system, and data processing resources. Selecting an instrument requires one to consider all these dimensions, and for some highly specific applications some high-end capabilities that may be unique to specific instrument manufacturers.

The rise of MS in the flavors and fragrances field and the corresponding pioneering work of Firmenich was reviewed in a previous article in CHIMIA. ${ }^{[1]}$ When it was published in 2014, gas chromatography (GC) hyphenated to single quadrupole mass spectrometry (SqMS) was the standard. Since then, MS has continued its evolution, improving its ease of use, displaying lower footprint, higher sensitivity and acquisition rate, and remarkably offering access to benchtop high resolution instruments with either Time of Flight or Orbitrap mass analyzers. The very high density of information achieved by today's mass spectrometers requires advanced data processing capabilities that all instrument providers are offering, which are often complemented by dedicated solutions enhancing the automation of the data processing work.

Through different examples of applications published after 2014 by Firmenich researchers and others, this article will illustrate many aspects of the use of MS in the F\&F domain, mostly focusing on quantification, and will provide with some views on directions where further developments are desired.

\section{Recent Applications of GC-MS for Volatiles}

Historically GC-MS was mostly used to identify molecules extracted from different ingredients. When coupled with GCOlfactometry, it contributed to the identification of impact molecules, and numerous researchers have published about this.[2] Because of their robustness, sensitivity, ease of use and limited artifact formation mostly in the ionization chamber, single quadrupoles are by far the most common MS coupled to gas chromatography. They have displaced the ion traps that were very popular in the 1990s but suffered from various limitations such as auto-ionization that impaired the reproducibility of mass spectra from instrument to instrument and consequently limited the efficiency of automatic identification based on standard mass spectral databases.

Single quadrupoles are standard low-cost benchtop MS that today are also used for quantification. Their linear range, $10^{3}$ for most applications with simple to mid-complex matrices, is significantly lower compared to the standard FID (typically $10^{7}$ ), however MS compensates with a good selectivity. The improved acquisition rate and its corollary the possibility to simultaneously conduct single ion monitoring and full scan acquisition in a same run enhanced the capabilities of single quadrupoles by combining identification and quantification capabilities. This feature is extremely useful when dealing for instance with analyses to check the compliance of ingredients. The high acquisition rate also enables the use of highly resolutive chromatographic techniques generating peaks as narrow as half-height width $<150 \mathrm{~ms}$, while maintaining the quantification capabilities that typically requires a minimum of seven acquisition points per chromatographic peak. As an illustration, a method for the routine quantification of 54 suspected allergens in fragrances was developed using comprehensive bidimensional GC-single quadrupole MS-FID (GCxGCSqMS-FID), ${ }^{[3]}$ demonstrating the capability of the new generation of single quadrupole MS to provide detection and quantification capabilities compatible with advanced chromatographic techniques. This improves the throughput of the analytical laboratories. This example also illustrates that there is still a need to complement MS capability with additional detectors: combining both MS and FID detection in a single run allows to significantly improve the quantification range, the MS being suitable at low concentrations $(2-100 \mathrm{mg} / \mathrm{kg})$ whereas the FID is required for higher concentration range (100-10000 mg/kg) where interferences are less prone to impact the quantification. This extended quantification range made it possible to quantify in a single run a large number of molecules, hence avoiding multiple dilutions of the sample and injections while reaching the same concentration range. As already mentioned, data processing is critically important to reach the required throughput and make the most of the available information. For this reason a specific decision tree was also provided to automatically process the data from GCxGCSqMS-FID.

Tan et al. ${ }^{[4]}$ also demonstrated the ability of today's robust and affordable single quadrupole MS to be included in complex instrumental configurations. Working with shower gel, a complex matrix, they developed a versatile instrument offering a selectable one- or two-dimensional GC-MS coupled with a FID and an olfactory detection port (1D/2D-FID/MS/O). While necessarily sacrificing some robustness of a standard GC-MS, this configuration allows to process multiple types of samples and was made possible thanks to MS having reached the level of robustness observed for many years on chromatographs.

Beyond single quadrupole, triple quadrupole mass spectrometry (MS/MS) offers improved sensitivity and selectivity. Combined with an efficient sample preparation method, it allows extremely low detection limits to be reached, which can be a critical capability for instance in toxicity assessment. An illustrative example is the quantification of limonene oxides sampled by automated solidphase microextraction and analyzed with a validated GC-MS/MS method, reaching an impressive $10-15 \mathrm{ng} / \mathrm{mL}$ limit of detection, and less than $5 \mathrm{ng} / \mathrm{mL}$ for carvone and carveol isomers. ${ }^{[5]}$ The very high selectivity of MS/MS is also a true asset to ensure fact-based decisions related to human exposure are properly made.

Still, sensitivity can be a limitation when the MS is expected to detect highly potent molecules like sulfur compounds. In such cases, the odor detection threshold (ODT) is so low (e.g. $4 \times 10^{-5} \mu \mathrm{g} / \mathrm{L}$ for methyl mercaptan) that the nose will detect it way before the MS can. The analytical chemist will have to improve the sensitivity of the MS detection by modifying the molecule to either improve the response factor of the substance or by stabilizing it to tolerate being concentrated on a trap. This derivatization step was for instance conducted to quantify hydrogen sulfide and methyl mercaptan in latrines. ${ }^{[6]}$ These molecules were trapped on a substrate impregnated with N-ethylmaleimide (NEM) that readily reacted with both hydrogen sulfide and methyl mercaptan to form much more stable NEM-derivatives that could be concentrated enough to allow proper quantification at real on-site concentration levels.

Another significant evolution of GC-MS is benchtop highresolution systems that have been brought to market by various instruments providers in recent years. Quadrupole-time of flight (Q-TOF) and Orbitrap mass spectrometers are nowadays available and are providing extra capabilities including an unprecedented selectivity, an ability to acquire full mass spectra of all the peaks eluting from the chromatographic column, with fast acquisition rate for Q-TOF (as high as $50 \mathrm{~Hz}$ ), allowing for in-depth investigation and search for trace amount of compounds. ${ }^{[7]}$ In this respect, dedicated data processing software such as Compound Discoverer, Mass Hunter or others are critically important and require advanced training for the users. The good compatibility of the MS spectra they generate with standard MS databases built 
from single quadrupole data is also a critical element for companies like Firmenich that have been building their own proprietary MS databases for decades. There are still some limitations in the application of such high-end instruments. High-resolution MS barely distinguishes isobaric molecules within, for example, the terpenes and sesquiterpenes families. In the context of industrial samples that can be mixtures of mixtures, e.g. essential oils in a perfume, so far no deconvolution solution solely based on MS fragmentation has proven to be efficient enough to distinguish with a high confidence isobaric molecules from the same chemical family even when corresponding chromatographic peaks are completely resolved. Other orthogonal information has to be considered, such as relative retention indices.

As powerful and straightforward as they are, the MS techniques should not relieve the analyst from following a set of good practices that ensure the quality of the information generated. Numerous reference documents are available in this area, and it is critically important that leading actors of the F\&F field promote them. Core precautions related to quantification best practices have for instance been published by Firmenich researchers, ${ }^{\left[{ }^{[8}\right.}$ which are especially important when dealing with complex matrices or multianalyte quantification. In addition to elementary precautions that include ensuring the suitability of the instrumentation, the purity of the internal and calibration standards and the sample preparation among others, the accuracy profile approach is especially relevant to validate analytical methods and we recommend its use. ${ }^{\text {[9] }}$

GC-MS is a mature technique, and the quality of today's instrumentation allows multiple applications and integration in complex analytical configurations. The recent availability of benchtop high-resolution instruments offers new possibilities, even if their robustness still needs to be proven. The most desirable outcomes are the ability to cover the entire range of analyte concentrations in a sample in a single injection for both identification and quantification purposes, with improved data processing including peak deconvolution, identification and reporting.

\section{The Rise of LCMS in F\&F, for Non-volatiles and be- yond}

As mentioned in the introduction, in 2021 non-volatile molecules are a full part of the F\&F solutions portfolio, and their increased usage has raised new analytical challenges. In addition, analytical laboratories are always looking for more efficiency and sample throughput, and liquid chromatography-mass spectrometry (LC-MS) offers numerous advantages also to analyze volatile substances, as we will see below. Consequently, the presence of LC-MS in F\&F analytical laboratories has become more common in the past decade, and applications are rapidly growing. Publications remain relatively rare, as for many aspects of industrial research. For example, LC-MS may be used for the discovery of taste modifiers, an activity which is also accelerated by the knowledge of taste receptors such as for umami perception. ${ }^{[10]}$ LC-MS is also useful for the characterization of profragrances or proflavors, which are by essence non-volatile molecules that release a volatile odorant fragment once cleaved by specific external triggers, ${ }^{[11]}$ or the characterization of polymers used for encapsulation. ${ }^{[12]}$

Extensive GC/MS databases of F\&F compounds have been built by Firmenich and other F\&F companies over many years, but this has not happened yet to the same extent for LC-MS/MS because of technical limitations, now partially overcome. Highresolution LC-MS is of great help for the still challenging identification of peaks. Publicly or commercially available databases such as mzcloud ${ }^{[13]}$ or METLIN ${ }^{[14]}$ contain as many as $500^{\prime} 000$ experimental MS/MS spectra. Unfortunately, none of them is dedicated to F\&F-related compounds. If an unknown peak cannot be found in MS/MS databases, useful tools based on in silico MS/MS predicted fragmentation can be used such as Sirius. ${ }^{[15]}$ Molecular networks generated by Global Natural Products Social molecular networking (GNPS) ${ }^{[16]}$ can group compounds by MS/MS similarity and hopefully by chemical family. This may help to identify unknown compounds that are close to a known compound in the molecular network. ${ }^{[17]}$

LC-MS also offers the advantage of improving the throughput of analytical laboratories for instance when working with aqueous samples. Providing that the target molecules, which may be volatile, are efficiently ionized by the MS source, LC-MS using reversed phase separation column allows to directly analyze watersolubilized substances, limiting the need for sample preparation. This is especially frequent for studies assessing the environmental impact of substances, such as the characterization of biodegradation residues or the development of specific ecotoxicological tests. A nice illustration is the development of in vitro tests to assess the bioconcentration factor of fragrance ingredients ${ }^{[18]}$ or the use of fish cell lines to assess the acute toxicity of fragrance molecules, ${ }^{[19]}$ both using LC-MS/MS capabilities to quantify the targeted fragrance substances in an aqueous media. In such cases LC-MS/MS allowed the required sensitivity to be achieved, typically in the $100 \mathrm{pg} / \mathrm{mL}$ to $\mathrm{ng} / \mathrm{mL}$ range while limiting the sample preparation to a simple addition of internal standard followed by filtration before injection, for a run-to-run pace as fast as 6 min for some substances.

Unfortunately, LC-MS applications of classical volatile F\&F molecules are limited by their ionization capabilities and not all are prone to provide a significant ionization yield in ESI or APCI sources. The lack of availability of a universal detector in liquid chromatography, contrary to GC where FID and electron impact ionization MS are covering the entire range of organic molecules, remains a hurdle.

Obviously, thinking about LC-MS seems straightforward when samples with substantial amounts of non-volatiles have to be analyzed. There are, however, cases for which GC-MS is still more appropriate, especially when the non-volatile sample is insoluble in any kind of solvent thus making it unsuitable for LC injection. This was, for instance, the case of a highly reticulated polymeric material used to encapsulate fragrances that was totally insoluble. The challenge was to quantify the amount of residual perfume material after the polymeric shell of the capsules was cleaned to ensure the reliability of further environmental tests to be conducted on the polymer. Pyrolysis-GC-MS (Py-GC-SqMS) proved to be a suitable solution, allowing to reproducibly break down the insoluble material into volatile compounds, while releasing the remaining perfume molecules and allowing their accurate quantification. ${ }^{[20]}$ It was the first time such a quantitative application was demonstrated and validated for Pyrolysis-GC-MS. This also illustrated the importance of having a comprehensive analytical toolbox to solve the challenges raised by the F\&F applications.

\section{Conclusion}

Through different examples, we have illustrated and confirmed the critical importance of mass spectrometry in F\&F laboratories. Not all of these applications can easily be transferred out of R\&D laboratories, and they have their own advantages and limitations (Table 1). However, we have observed that automation and digitalization significantly increases the accessibility of these techniques in analytical laboratories involved in production. Advanced chromatography-MS is no longer only an R\&D playground. Nowadays instruments and expert applications are also present in quality assurance/quality control (QA/QC) as well as in application laboratories. It is, however, essential to remember that the proper use of instruments always requires properly trained experimenters, able to set-up fit-for-purpose methods and to interpret and challenge the data provided by the instruments to extract the appropriate information. Keeping in mind this prerequisite, MS is an essential part of today's F\&F analytical laboratories, and in the future its application scope will continue to expand. 


\begin{tabular}{|c|c|c|}
\hline Technique & Advantages & Limitations \\
\hline GC-FID & $\begin{array}{l}\text { - Robust } \\
\left.\text { - Highly linear ( } 10^{7} \text { concentration range }\right) \\
\text { - Sensitive } \\
\text { - Universal detector for organic molecules } \\
\text { - Easy to operate } \\
\text { - Cheap }\end{array}$ & $\begin{array}{l}\text { - Not selective } \\
\text { unknowns } \\
\text { - Low density of information }\end{array}$ \\
\hline GC-SqMS & $\begin{array}{l}\text { - Robust } \\
\text { - Sensitive (ppb range in single ion } \\
\text { monitoring mode) } \\
\text { - Selective } \\
\text { - Easy to operate } \\
\text { - Availability of global MS databases } \\
\text { - Nearly universal for organic molecules } \\
\text { - Suitable for identification of unknowns } \\
\text { - Simultaneous quantification and } \\
\text { identification } \\
\text { - Affordable }\end{array}$ & $\begin{array}{l}\text { - Limited linearity range } \\
\left(10^{3} \text { concentration range) }\right. \\
\text { - Limited to volatile compounds, with or } \\
\text { without derivatization } \\
\text { - Limited sensitivity when in full scan } \\
\text { mode }\end{array}$ \\
\hline $\begin{array}{l}\text { GCxGC- } \\
\text { SqMS-FID }\end{array}$ & $\begin{array}{l}\text { - High selectivity } \\
\text { - Simultaneous identification and } \\
\text { quantification } \\
\text { - Less injections required to cover an } \\
\text { extended concentration range }\end{array}$ & $\begin{array}{l}\text { - Robustness is a challenge } \\
\text { - Requires } \mathrm{N}_{2} \text { as cooling agent for } \\
\text { compounds with volatility lower than C9 }\end{array}$ \\
\hline $\begin{array}{l}\text { 1D/2D-FID/ } \\
\mathrm{MS} / \mathrm{O}\end{array}$ & $\begin{array}{l}\text { - Versatility combining the advantages of } \\
\text { FID, SqMS and olfactometry }\end{array}$ & $\begin{array}{l}\text { - Fragile instrument since complex set up } \\
\text { - Requires advanced skill to operate and } \\
\text { maintain it }\end{array}$ \\
\hline GC-MS/MS & $\begin{array}{l}\text { Improved sensitivity and selectivity } \\
\text { compared to SqMS, especially in } \\
\text { complex matrices }\end{array}$ & $\begin{array}{l}\text { - More complex to operate than SqMS } \\
\text { - Costly }\end{array}$ \\
\hline GC-Q-TOF & $\begin{array}{l}\text { - High selectivity } \\
\text { - Fast acquisition rate } \\
\text { - Full MS systematically acquired } \\
\text { - Allows for post-analysis search of new } \\
\text { targets molecules }\end{array}$ & $\begin{array}{l}\text { - Specific footprint } \\
\text { - Requires highly skilled operator } \\
\text { - Isobaric compounds hardly } \\
\text { distinguishable } \\
\text { - Advanced data processing is a must } \\
\text { - Costly }\end{array}$ \\
\hline GC-Orbitrap & $\begin{array}{l}\text { - High selectivity } \\
\text { - Full MS systematically acquired } \\
\text { - Allows for post-analysis search of new } \\
\text { targets molecules } \\
\text { - Standard footprint }\end{array}$ & $\begin{array}{l}\text { - Requires highly skilled operator } \\
\text { - Isobaric compounds hardly identified } \\
\text { - Advanced data processing is a must } \\
\text { - Costly }\end{array}$ \\
\hline Py-GC-SqMS & $\begin{array}{l}\text { - Sensitive } \\
\text { - Reproducible } \\
\text { - Quantitative } \\
\text { - Compatible with non-soluble and non } \\
\text { volatile samples }\end{array}$ & $\begin{array}{l}\text { - Results complex to interpret } \\
\text { - Pyrolysis not suitable for all samples } \\
\text { - Samples delicate to prepare }\end{array}$ \\
\hline LC-MS & $\begin{array}{l}\text { - Robust } \\
\text { - Selectivity highly tunable } \\
\text { - Higher throughput than GC-MS for } \\
\text { aqueous samples } \\
\text { - Affordable }\end{array}$ & $\begin{array}{l}\text { - Not suitable for all molecules } \\
\text { - Very variable ionization yields } \\
\text { - Not very sensitive compared to GC-SqMS } \\
\text { - Instrument dependant mass spectra } \\
\text { - Structure elucidation rarely achievable }\end{array}$ \\
\hline LC-MS/MS & $\begin{array}{l}\text { - Robust } \\
\text { - Selectivity highly tunable } \\
\text { - Sensitive } \\
\text { - Quantitative } \\
\text { - Compatible with high throughput methods }\end{array}$ & $\begin{array}{l}\text { - Not suitable for all molecules } \\
\text { - Very variable ionization yields } \\
\text { - Limited identification capabilities } \\
\text { for unknowns } \\
\text { - Costly }\end{array}$ \\
\hline $\begin{array}{l}\text { LC-MS-High } \\
\text { resolution MS }\end{array}$ & $\begin{array}{l}\text { - Robust } \\
\text { - High selectivity } \\
\text { - Sensitive } \\
\text { - Quantitative } \\
\text { - Identification through advanced mass } \\
\text { spectra comparison with global databases }\end{array}$ & $\begin{array}{l}\text { - Costly } \\
\text { - Requires highly skilled operator } \\
\text { - Investment in advanced data processing } \\
\text { capabilities is a must }\end{array}$ \\
\hline
\end{tabular}

Table 1. Advantages and limitations of the different analytical methods mentioned in the text. 
There is no doubt that the new generation of benchtop instruments will facilitate exciting new discoveries that will push the boundaries F\&F science beyond its current limit. Automation, advanced data processing, environmental footprint and miniaturization still have a great potential for improvement. Significant progress is expected on these aspects.

Last but not least, MS has its own limitations, and solving scientific challenges very often requires the combination of MS approaches with orthogonal techniques such as nuclear magnetic resonance (NMR). Analytical chemistry experts must be versatile and not limit themselves to one technique, no matter how good it is. This is more than necessary to succeed in solving today's challenges in areas as diverse as biochemical pathways elucidation, natural occurrence demonstration, performance of F\&F delivery systems or environmental impact to name just a few.

\section{Acknowledgments}

The author would like to thank Dr. Eric Frerot and Dr. Olivier Haefliger for their insights and critical review of this paper. He also thanks M. Philippe Merle who provided the initial version of Fig. 1.

Received: November 19, 2021

[1] E. Frerot, L. Wunsche, CHIMIA 2014, 68, 160, https://doi.org/10.2533/chimia.2014.160.

[2] a) P. Pollien, A. Ott, F. Montigon, M. Baumgartner, R. MunozBox, A. Chaintreau, J. Agric. Food Chem. 1997, 45, 2630, https://doi.org/10.1021/jf960885r; b) J. A. Piornos, D. P. Balagiannis, L. Methven, E. Koussissi, E. Brouwer, J. K. Parker, J. Agric. Food Chem. 2020, 68, 37, https://doi.org/10.1021/acs.jafc.0c03902; c) N. Baldovini, A. Chaintreau, Nat. Prod. Rep. 2020, 37, 1589, https://doi.org/10.1039/d0np00020e.

[3] E. Belhassen, D. Bressanello, P. Merle, E. Raynaud, C. Bicchi, A. Chaintreau, C. Cordero, Flavour Fragr. J. 2018, 33, 63, https://doi.org/10.1002/ffj.3416.

[4] H. P. Tan, T. S. Wan, C. L. S. Min, M. Osborne, K. H. Ng, J. Chromatogr. A 2014, 1333, 106, https://doi.org/10.1016/j.chroma.2014.01.073.

[5] M. E. Emberger, J. Lin, J. Pika, I. Christ, B. Eigenbrodt, Flavour Fragr. J. 2019, 34, 52, https://doi.org/10.1002/ffj.3479.

[6] a) C. J. Chappuis, R. Huber, Y. Niclass, C. Starkenmann, Flavour Fragr. J. 2018, 33, 313, https://doi.org/10.1002/ffj.3450; b) C. J. Chappuis, Y. Niclass, C. Vuilleumier, C. Starkenmann, Environ. Sci. Technol. 2015, 49, 6134, https://doi.org/10.1021/acs.est.5b00692.

[7] S. Belarbi, M. Vivier, W. Zaghouani, A. D. Sloovere, V. Agasse-Peulon, P. Cardinael, Food Chem. 2021, 359, 129932, https://doi.org/10.1016/j.foodchem.2021.129932.

[8] F. Begnaud, A. Chaintreau, Phil. Trans. Royal Soc. A: Math. Phys. Engin. Sci. 2016, 374, https://doi.org/10.1098/rsta.2015.0365.

[9] a) P. Hubert, J. J. Nguyen-Huu, B. Boulanger, E. Chapuzet, P. Chiap, N. Cohen, P. A. Compagnon, W. Dewe, M. Feinberg, M. Lallier, M. Laurentie, N. Mercier, G. Muzard, C. Nivet, L. Valat, STP Pharma Practiques 2007, 13, 101; b) M. Feinberg, J. Chromatogr. A 2007, 1158, 174 , https://doi.org/10.1016/j.chroma.2007.02.021.

[10] a) G. Servant, E. Frerot, 'Pharmacology of the Umami Taste Receptor', in 'Handbook of Experimental Pharmacology', Springer, Berlin, Heidelberg, 2021, https://doi.org/10.1007/164_2021_439; b) E. Frerot, N. Neirynck, I. Cayeux, Y. H. Yuan, Y. M. Yuan, J. Agric. Food Chem. 2015, 63, 7161, https://doi.org/10.1021/acs.jafc.5b02359.
[11] a) A. Herrmann, CHIMIA 2020, 74, 39 , https://doi.org/10.2533/chimia.2020.39; b) G. Womack, A. Herrmann, WO2021123144, 2021; c) G. B. Womack, B. Indradas, WO2020127708, 2020.

[12] a) D. Berthier, WO2021185724, 2021; b) D. Berthier, M. Jacquemond, L. Ouali, A. Elabbadi, A. Nicolae, WO2020127743, 2020; c) L. Ouali, D. Berthier, M. Jacquemond, A. Nicolae, A. Elabbadi, WO2021023647, 2021.

[13] https://www.mzcloud.org/.

[14] C. Guijas, J. R. Montenegro-Burke, X. Domingo-Almenara, A. Palermo, B. Warth, G. Hermann, G. Koellensperger, T. Huan, W. Uritboonthai, A. E. Aisporna, D. W. Wolan, M. E. Spilker, H. P. Benton, G. Siuzdak, Anal. Chem. 2018, 90, 3156, https://doi.org/10.1021/acs.analchem.7b04424.

[15] K. Dührkop, M. Fleischauer, M. Ludwig, A. A. Aksenov, A. V. Melnik, M. Meusel, P. C. Dorrestein, J. Rousu, S. Böcker, Nat. Meth. 2019, 16, 299 , https://doi.org/10.1038/s41592-019-0344-8.

[16] M. Wang, J. J. Carver, V. V. Phelan, L. M. Sanchez, N. Garg, Y. Peng, D. D. Nguyen, J. Watrous, C. A. Kapono, T. Luzzatto-Knaan, C. Porto, A. Bouslimani, A. V. Melnik, M. J. Meehan, W.-T. Liu, M. Crüsemann, P. D. Boudreau, E. Esquenazi, M. Sandoval-Calderón, R. D. Kersten, L. A Pace, R. A. Quinn, K. R. Duncan, C.-C. Hsu, D. J. Floros, R. G. Gavilan, K. Kleigrewe, T. Northen, R. J. Dutton, D. Parrot, E. E. Carlson, B. Aigle, C. F. Michelsen, L. Jelsbak, C. Sohlenkamp, P. Pevzner, A. Edlund, J. McLean, J. Piel, B. T. Murphy, L. Gerwick, C.-C. Liaw, Y.-L. Yang, H.-U. Humpf, M. Maansson, R. A. Keyzers, A. C. Sims, A. R. Johnson, A. M. Sidebottom, B. E. Sedio, A. Klitgaard, C. B. Larson, C. A. Boya P, D. Torres-Mendoza, D. J. Gonzalez, D. B. Silva, L. M. Marques, D. P. Demarque, E. Pociute, E. C. O'Neill, E. Briand, E. J. N. Helfrich, E. A. Granatosky, E. Glukhov, F. Ryffel, H. Houson, H. Mohimani, J. J. Kharbush, Y. Zeng, J. A. Vorholt, K. L. Kurita, P. Charusanti, K. L. McPhail, K. F. Nielsen, L. Vuong, M. Elfeki, M. F. Traxler, N. Engene, N. Koyama, O. B. Vining, R. Baric, R. R. Silva, S. J. Mascuch, S. Tomasi, S. Jenkins, V. Macherla, T. Hoffman, V. Agarwal, P. G. Williams, J. Dai, R. Neupane, J. Gurr, A. M. C. Rodríguez, A. Lamsa, C Zhang, K. Dorrestein, B. M. Duggan, J. Almaliti, P.-M. Allard, P. Phapale, L.-F. Nothias, T. Alexandrov, M. Litaudon, J.-L. Wolfender, J. E. Kyle, T. O. Metz, T. Peryea, D.-T. Nguyen, D. VanLeer, P. Shinn, A. Jadhav, R. Müller, K. M. Waters, W. Shi, X. Liu, L. Zhang, R. Knight, P. R. Jensen, B. Ø. Palsson, K. Pogliano, R. G. Linington, M. Gutiérrez, N. P. Lopes, W. H. Gerwick, B. S. Moore, P. C. Dorrestein, N. Bandeira, Nat. Biotechnol. 2016, 34, 828 , https://doi.org/10.1038/nbt.3597

[17] P. M. Allard, T. Peresse, J. Bisson, K. Gindro, L. Marcourt, V. C. Pham, F. Roussi, M. Litaudon, J. L. Wolfender, Anal. Chem. 2016, 88, 3317, https://doi.org/10.1021/acs.analchem.5b04804.

[18] a) C. Kropf, F. Begnaud, S. Gimeno, F. Berthaud, C. Debonneville, H. Segner, Environ. Toxicol. Chem. 2020, 39, 2396, https://doi.org/10.1002/etc.4872; b) H. Schug, J. Maner, F. Begnaud, F. Berthaud, S. Gimeno, K. Schirmer, A. Županič, Environ. Sci. Technol. 2019, 53, 12062, https://doi.org/10.1021/acs.est.9b04281.

[19] H. Schug, J. Maner, M. Hulskamp, F. Begnaud, C. Debonneville, F. Berthaud, S. Gimeno, K. Schirmer, Altern. Animal Exp. 2019, 37, 37, https://doi.org/10.14573/altex.1905032.

[20] G. Gasparini, S. Semaoui, J. Augugliaro, M. Seyfried, F. Begnaud, Molecules 2020, 25, https://doi.org/10.3390/molecules 25030718 .

\section{License and Terms}

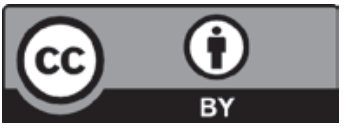

This is an Open Access article under the terms of the Creative Commons Attribution License CC BY 4.0. The material may not be used for commercial purposes.

The license is subject to the CHIMIA terms and conditions: (https://chimia.ch/chimia/about).

The definitive version of this article is the electronic one that can be found at https://doi.org/10.2533/chimia.2022.68 